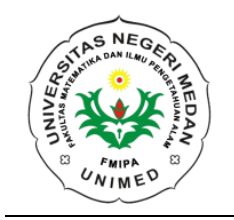

\author{
JURNAL EINSTEIN \\ Jurnal Hasil Penelitian Bindang Fisika \\ Available online http://jurnal.unimed.ac.id/2012/index.php/inpafi \\ e-issn: $2407-747 x$, p-issn $2338-1981$
}

\title{
PENENTUAN LAPISAN KERAS UNTUK KELAYAKAN PEMBANGUNAN GEDUNG BERTINGKAT MENGGUNAKAN METODE GEOLISTRIK RESISTIVITAS DI PESISIR PANTAI KAHONA KABUPATEN TAPANULI TENGAH
}

\author{
Abdul Aziz Alfaiz dan Drs.Juniar Hutahaean, M.Si \\ Jurusan Fisika, Fakultas Matematika dan Ilmu Pengetahuan Alam, Universitas Negeri Medan, \\ Indonesia \\ Abdulazizalfaiz.aaa@gmail.com \\ Diterima September 2017; Disetujui Oktober 2017; Dipublikasikan November 2017
}

\begin{abstract}
ABSTRAK
Penelitian ini bertujuan untuk menentukan nilai resistivitas lapisan tanah kemudian mengkaitkan dengan kelayakan pembangunan gedung bertingkat pada daerah pesisir pantai Kahona Kabupaten Tapanuli Tengah. Berdasarkan analisa nilai resistivitasnya penelitian ini menggunakan Metode Geolistrik Konfigurasi Schlumberger. Variasi nilai tahanan jenis akan diperoleh jika jarak masing-masing elektroda diubah, kemudian diperoleh nilai tahanan jenis yang bukan nilai sebenarnya tetapi berupa tahanan jenis semu. Data yang diperoleh menggunakan alat Geolistrik ARES-G4 v4.7 SN: 0609135 berupa nilai resistivitas semu, kemudian diubah menjadi nilai resistivitas. Data yang diperoleh dibuat menjadi gambar model penampang dua dimensi dengan menggunakan software Res2Dinv. Hasil penelitian menunjukkan bahwa daerah pesisir pantai Kahona memiliki nilai resistivitas yang masih rendah sekitar 4,84 $\Omega \mathrm{m}$ sampai $105 \Omega \mathrm{m}$ pada lintasan pertama dan $0,865 \Omega \mathrm{m}$ sampai $165 \Omega \mathrm{m}$ pada lintasan kedua. Berdasarkan dari nilai resistivitas yang diperoleh, daerah tersebut mengandung liat/lempung pada kedalaman 1,25 - 28,7 meter. Berdasarkan hasil penelitian ini daerah pesisir pantai Kahona belum dapat direkomendasikan untuk pembangunan gedung bertingkat karena tidak terdapat lapisan keras pada struktur batuan bawah permukaan tanah. Pengukuran nilai resistivitas setiap lintasan memiliki persentasi kesalahan 23,6 - 24,2 \%.
\end{abstract}

Kata Kunci : Geolistrik, Konfigurasi Schlumberger, Lapisan Keras.

\section{PENDAHULUAN}

Secara geografis Indonesia membentang

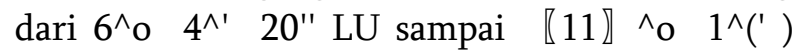
23" LS dan 『95》^ $\mathrm{o} 6^{\wedge^{\prime}} 30^{\prime \prime}$ BT sampai 『141 】^o $1^{\wedge^{\prime}} 54^{\prime \prime} \mathrm{BT}$, terdiri dari pulau-pulau besar dan kecil yang jumlahnya kurang lebih 17.504 pulau. Tiga perempat wilayahnya adalah laut (5,9 juta $\mathrm{Km} 2)$, dengan panjang garis pantai $95.161 \mathrm{Km}$, terpanjang kedua setelah Kanada. Dengan jumlah pulau yang kurang lebih 17.504 pulau, maka persoalan pemanfaatan lahan pantai ini merupakan topik yang harus dibahas untuk pengembangan pembangunan daerah pesisir di Indonesia.

Berkaitan dengan hal ini pemanfaatan sumberdaya di daerah Indonesia sendiri masih terfokus pada pemanfaatan sumberdaya yang ada di daratan saja, sedangkan sumberdaya lautan di Indonesia masih sedikit yang diperhatikan. Bila ditinjau secara dalam, 
sumberdaya lautan memiliki potensi yang lebih besar dibandingkan dengan sumberdaya yang ada di daratan yang relatif terbatas.

Wilayah pesisir memiliki potensi yang sangat spesifik dikarenakan wilayah pesisir merupakan daerah peralihan antara daratan dan lautan. Sehingga sumberdaya yang ada di wilayah pesisir merupakan interaksi dari keduanya. Seperti kondisi cuaca, lahan,serta ketersediaan sumber air mineral yang memiliki ciri tersendiri.

Pantai adalah jalur yang merupakan pertemuan antara darat dan laut. Daerah pantai ini mempunyai ciri geosfer yang khusus, kearah laut dibatasi oleh pengaruh fisik laut dan sosial ekonomi bahari, sedangkan kearah darat dibatasi oleh pengaruh alami dan kegiatan manusia terhadap lingkungan darat (Pramudya A, 2008).

Deretan pantai barat pulau Sumatera memiliki potensi alam yang sangat strategis dikarenakan wilayah pantai langsung berpapasan dengan samudra Hindia yang memiliki ombak besar dan pasir pantai yang bagus. Maka pembangunan sector pariwisata menjadi salah satu cara untuk memanfaatkan sumber daya wilayah pesisir. Kabupaten Tapanuli Tengah adalah salah satu daerah yang perlu ditingkatkan pembangunan daerahnya dikarenakan potensi alam yang ada sangat besar dan belum tersentuh oleh pemerintah pusat. Namun akhir-akhir ini kabupaten Tapanuli Tengah mulai tersentuh oleh pemerintah pusat dan itu tentu saja menjadi perhatian bagi publik untuk mengetahui potensi yang ada di kabupaten Tapanuli Tengah. (Badan Pusat Statistik, Kabupaten Tapanuli Tengah, 2012).

Sektor pariwisata di kabupaten Tapanuli Tengah, khususnya di kecamatan Andam Dewi desa Lobu Tua menjadi sorotan publik dikarenakan memiliki potensi pariwisata laut yang bagus yaitu lokasi pariwisata pantai Kahona. Tetapi pembangunan di daerah tersebut masih dibilang belum memenuhi standar untuk masuk ke pariwisata nasional dikarenakan fasilitas sarana dan prasarana seperti akses jalan, penginapan, hotel, restoran, dan lainnya masih kurang di daerah tersebut. Pembangunan Prasarana seperti gedung merupakan salah satu tujuan untuk meningkatkan sektor pariwisata di daerah ini. Maka faktor seperti kekerasan, kestabilan, serta tekstur tanah perlu diperhatikan kelayakannya dalam proses pembangunan terutama di daerah pesisir pantai.

Pondasi suatu bangunan dinyatakan layak apabila terdapat lapisan batuan dasar berkekar terisi tanah kering dengan nilai resistivitas lebih dari $300 \Omega \mathrm{m}$ kemudian dilakukan pemadatan tanah agar mendapat tekstur lapisan tanah yang kuat untuk pondasi dari suatu bangunan. (Syamsurizal dkk.2013)

Penelitian tentang lapisan keras sebelumnya telah dilakukan oleh Selawati (2013) dengan menggunakan metode geolistrik konfigurasi Schlumberger di daerah pesisir pantai Sialang Buah Kabupaten Serdang Bedagai menunjukkan bahwa daerah pesisir pantai Sialang Buah memiliki nilai resistivitas yang sangat rendah yaitu rata-rata $1,11 \Omega \mathrm{m}$ sampai $5,23 \Omega \mathrm{m}$ pada tiga lintasan. Berdasarkan nilai resistivitas yang diperoleh, daerah tersebut mengandung tanah liat/lempung dan tanah lanau pada kedalaman 1,25 - 12,4 m. Berdasarkan hasil penelitian di daerah ini, maka daerah ini belum dapat direkomendasikan untuk pembangunan gedung bertingkat karena tidak adanya lapisan keras dan struktur batuan pada bawah permukaan.

Penerapan geolistrik telah dilakukan untuk kegiatan dibidang teknik sipil dengan menggunakan metode resistivitas konfigurasi Schlumberger sebagai bagian studi awal kegiatan pembanguan pondasi gedung bertingkat (Syamsurizal dkk.2013).

Metode geolistrik merupakan salah satu metode untuk penyelidikan tanah, metode ini memiliki kelebihan baik dalam hal akurasi juga lebih murah, dan cepat. Metode ini mengalami perkembangan cukup baik sehingga penggunannya tidak terbatas pada eksplorasi saja tetapi juga sudah banyak digunakan pada masalah lingkungan dan geoteknik. Prinsipnya yaitu mengamati perlapisan batuan berdasarkan perbedaan sifat konduktifitas batuan atau mengamati adanya anomali yaitu perbedaan besaran fisis dari benda yang dicari dengan tanah yang menutupinya. Besaran fisis untuk metode geolistrik tahanan jenis adalah sifat listrik (Telford dkk,1990).

Konfigurasi Schlumberger memiliki kelemahan pada pembacaan tegangan pada 
elekroda potensial lebih kecil terutama jika jarak arus yang relatif jauh. Sedangkan keunggulan dari konfigurasi Schlumberger memiliki kemampuan untuk mendeteksi adanya nonhomogenitas lapisan batuan pada permukaan, yaitu dengan membandingkan nilai resistivitas semu ketika terjadi perubahan jarak elektroda arus. Metode geolistrik konfigurasi Schlumberger adalah metode yang paling sering digunakan untuk mengetahui nilai ketebalan dan tahanan jenis batuan bawah permukaan.

Ditinjau dari pembangunan sector pariwisata yang ada di Pantai Kahona Desa Lobu Tua Kecamatan Andam Dewi Kabupaten Tapanuli Tengah masih harus lebih ditingkatkan pada pembangunan sarana dan prasarana. Terutama pembangunan lokasi penginapan seperti Hotel, resort dan lain-lain. Sehubungan dengan masalah ini maka penelitian tentang lapisan tanah di daerah tersebut sangat diperlukan agar pembangunan di daerah tersebut dapat diketahui perbandingan antara massa bangunan dengan kondisi permukaan tanahnya.

\section{METODE PENLITIAN}

Dari beberapa konfigurasi geolistrik metode tahanan jenis yang ada, akan digunakan konfigurasi Schlumberger. Dimana pada konfigurasi Schlumberger ini elektroda-elektroda potensial diam pada suatu tempat pada garis sentral $A B$ sedangkan elektroda-elektroda arus digerakkan secara simetris keluar dalam langkahlangkah tertentu dan sama. Pemilihan konfigurasi ini disasarkan atas prinsip kemudahan baik dalam pengambilan data maupun dalam analisisnya. Cara pengambilan datanya adalah sebagai berikut:

1. Mendownload data dari Ares.

2. Mengeksport data ke Res2Dinv.

3. Mengolah data menggunakan Res2Dinv.

Dari data pengukuran dan perhitungan di lapangan kemudian diinterpretasikan menggunakan Software Res2Dinv untuk memperlihatkan profil bawah permukaan area yang diukur. Software Res2Dinv (2D) digunakan untuk menampilkan profil 2 dimensi sehingga data pengukuran di lapangan menggunakan konfigurasi mapping. Langkahlangkah sebagai berikut :

1. Sebelum kita menjalakan Software Res2Dinv terlebih dahulu data yang kita akan interpretasi ditulis kedalam notepad dengan susunan penulisan sebagai berikut:

- Line 1 adalah Nama Survey. >>> (Data Awal Sounding Mapping)

- Line 2 adalah spasi antara kedua elektroda potensial (C1 dan C2). >>> $(10,0)$.

- Line 3 adalah jenis susunan konfigurasi yang digunakan (Wenner $=1$, Pole-Pole $=2$, Dipole-dipole $=3$, Pole-Dipole $=6$, Schlumberger $=7$ ) >>>(7).

- Line 4 adalah jumlah total data pengukuran (Datum Points)

- Line 5 lokasi data untuk data pengukuran (Datum Points)

- Line 6 ketik 0 >>> (0).

- Line 7 adalah memasukkan data pengukuran dan perhitungan yaitu jarak elektroda arus (s) [jarak antara titik pusat dengan elektroda arus], jarak antara dua elektroda potensial (C1 dan C2), lintasan pengukuran (n1, n2, n3 dan n4) dan nilai resistivitas semu yang diperoleh dari perhitungan (ditulis berurutan) begitu juga untuk data berikutnya.

2. Jalankan Program Res2Din

3. Pilih file $>>$ Read Data File dan Klik, kemudian ketika ada pernyataan Klik OK.

4. Kemudian pilih Display > Least Squares Inversion, maka dilayar akan ditampilkan profil lapisan bawah permukaan.

5. Selesai. (Soebowo,2009) 
Abdul Aziz Alfaiz dan Drs.Juniar Hutahaean, M.Si, Penentuan Lapisan Keras untuk Kelayakan Pembangunan Gedung Bertingkat Menggunakan Metode Geolistrik Resistivitas Di Pesisir Pantai Kahona Kabupaten Tapanuli Tengah

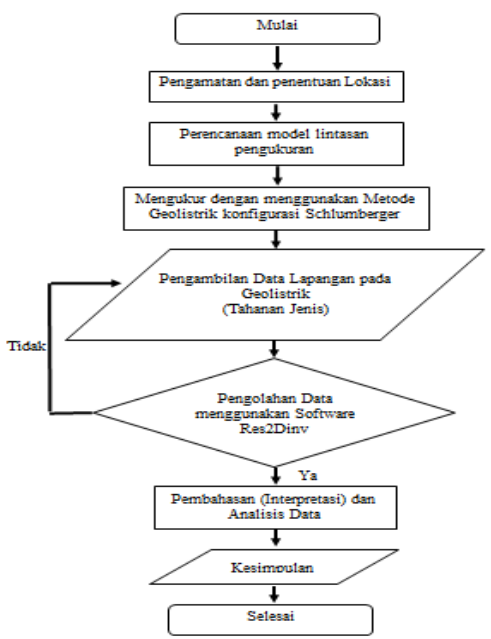

Gambar 1. Diagram Alir Pelaksanaan Penelitian

Gambar 1 merupakan diagram alir dalam pelaksanaan penelitian mulai dari penentuan lokasi yang sudah ditentukan kemudian menggunakan Geolistrik dengan konfigurasi Schlumberger agar memperoleh data berupa nilai tahanan jenis semu kemudian menginterpretasikan data dengan menggunakan software Res2Dinv agar diperoleh nilai resistivitas dan membandingkannya dengan nilai resistivitas batuan yang sudah ditentukan , kemudian membuat kesimpulan dari hasil data yang di peroleh.

Pada rumusan pengukuran besaran $\mathrm{V}$ pada rumusan potensial secara pengukuran dapat dinyatakan sebagai beda potensial $\delta \mathrm{V}$ antara potensial pada kondisi tanpa arus (V0) dan pada kondisi dengan arus (V1), yaitu dengan pengukuran potensial diantara elektroda P1 dan P2 (elektroda potensial), selanjutnya mengukur kuat arus yang mengalir diantara elektroda C1 dan C2 (elektroda arus). Konfigurasi yang digunakan dalam penelitian ini adalah Metode Schlumberger dengan menggunakan persamaan 1 :

$$
\begin{aligned}
& \delta V=\frac{\rho_{a}}{k} I \\
& \left|V_{1}-V_{0}\right|=\frac{\rho}{k} I
\end{aligned}
$$

Maka resistivitas semu $\left(\rho_{a}\right)$ di titik pengukuran dapat diperkirakan memalui rumusan : $\rho_{a}=\pi n(n+1) a \frac{\left|V_{1}-V_{0}\right|}{I}$

\section{Dimana :}

$\mathrm{K}=\pi \mathrm{n}(\mathrm{n}+1) \mathrm{a}$ adalah faktor geometri untuk konfigurasi Wenner-Schlumberger

$\mathrm{a}=$ Jarak antara elektroda P1 dan P2

$\mathrm{a}=(\mathrm{P} 1-\mathrm{P} 2)$ jarak spasi terkecil elektroda

$\mathrm{n}=$ Bilangan bulat $(\mathrm{n}=1,2,3, \ldots)$

$\mathrm{n}=(\mathrm{C} 1-\mathrm{P} 1) /(\mathrm{P} 1-\mathrm{P} 2)$

Data yang diperoleh sebelumnya dimasukkan ke dalam tabel pengambilan data lapangan dalam bentuk tabel berikut pada lintasan sebelum diolah dengan software Res2Dinv. Tabel hasil nilai resistivity dapat di lihat pada lampiran.

\section{Lintasan Pengukuran}

- Jarak elektroda :5 meter

- Koordinat Lintasan :

- Metode Schumberger :

Tabel 1. Input data hasil nilai resistivitas semu yang diperoleh

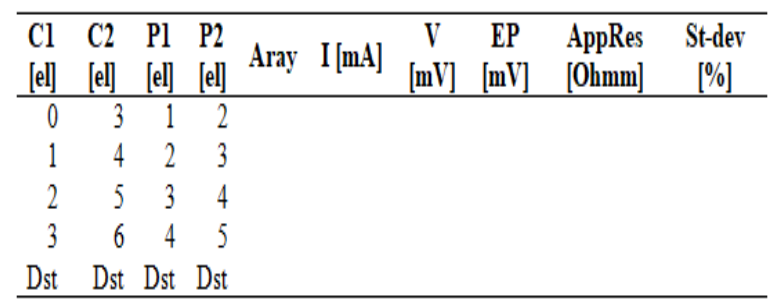

\section{HASIL DAN PEMBAHASAN}

Setelah dilakukan pengambilan data dengan menggunakan alat geolistrik (Resistivity Meter), ARES-G4 v4,7 SN: 0609135 (Autematic Resistivity System), GPS (Global Position System), di kedua lintasan yang telah ditentukan kemudian dilakukan pengunduhan data maka didapatkan hasil data tentang resistivitas dari tiap-tiap titik, kemudian data tersebut dikalikan dengan faktor geometri (konfigurasi Schumberger) umtuk mendapatkan nilai resistivitas semu 『( $\left.\rho \rrbracket \_s\right)$ yang akan digunakan dalam membuat kontur dengan menghubungkan tiap-tiap nilai resistivitas semu $\llbracket\left(\rho \rrbracket \_s\right)$ tersebut maka diperoleh data sebagai berikut : 
Tabel 2. Nilai setiap koordinat lintasan

\begin{tabular}{|c|c|c|c|c|}
\hline Lintasan 1 & $\begin{array}{l}\text { Waktu } \\
\text { (WIB) }\end{array}$ & ALT & Posisi & $\begin{array}{l}\text { Resistivitas } \\
\text { Semu }(\Omega \mathrm{m})\end{array}$ \\
\hline Letak Geolistrik & 08.56 & $18 \mathrm{~m} \mathrm{dpl}$ & $\begin{array}{l}\mathrm{N} 02^{\circ} 2^{\prime} 27.30^{\prime \prime \prime} \\
\mathrm{E} 98^{\circ} 21^{\prime} 3.16^{\prime \prime}\end{array}$ & \multirow{3}{*}{$4,84-105 \Omega \mathrm{m}$} \\
\hline Elektroda 1 & 08.53 & $18 \mathrm{~m} \mathrm{dpl}$ & $\begin{array}{l}\mathrm{N} 02^{\circ} 2^{\prime} 28.50^{\prime \prime} \\
\mathrm{E} 98^{\circ} 21^{\prime} 0.61^{\prime \prime}\end{array}$ & \\
\hline Elektroda 32 & 08.58 & $16 \mathrm{~m} \mathrm{dpl}$ & $\begin{array}{l}\mathrm{N} 02^{\circ} 2^{\prime} \quad 25.51^{\prime \prime \prime} \\
\mathrm{E} 98^{\circ} 21^{\prime} 5.24^{\prime \prime}\end{array}$ & \\
\hline Lintasan 2 & $\begin{array}{l}\text { Waktu } \\
\text { (WIB) }\end{array}$ & ALT & Posisi & $\begin{array}{l}\text { Resistivitas } \\
\text { Semu }(\Omega \mathrm{m})\end{array}$ \\
\hline Letak Geolistrik & 11.11 & $14 \mathrm{~m} \mathrm{dpl}$ & $\begin{array}{l}\text { N } 02^{\circ} 2^{\prime} 23.65^{\prime \prime} \\
\text { E } 98^{\circ} 21^{\prime} 7.81^{\prime \prime}\end{array}$ & \multirow{3}{*}{$0,865-165 \Omega \mathrm{m}$} \\
\hline Elektroda 1 & 11.09 & $20 \mathrm{~m} \mathrm{dpl}$ & $\begin{array}{l}\text { N } 02^{\circ} 2^{\prime} 25.51^{\prime \prime} \\
\text { E } 98^{\circ} 21^{\prime} 5.24^{\prime \prime}\end{array}$ & \\
\hline Elektroda 32 & 11.16 & $16 \mathrm{~m} \mathrm{dpl}$ & $\begin{array}{l}\text { N } 02^{\circ} 2^{\prime} 22.02^{\prime \prime} \\
\text { E } 98^{\circ} 21^{\prime} 9.32^{\prime \prime}\end{array}$ & \\
\hline
\end{tabular}

Tampilan 2-D hasil dari pengelolahan data dengan Res2Dinv tersebut terdiri dari tiga kontur Isoresistivitas pada penampang kedalaman semu (Pseudodepth section). Penampang yang pertama menunjukkan kontur resistivitas semu pengukuran (measured apparent resistivity), yaitu data resistivitas dari hasil perhitungan (calculated apparent resistivity), dan penampang yang ketiga adalah kontur resistivitas yang sebenarnya yang diperoleh setelah melalui proses pemodelan inversi (inversi model resistivity section).

Pada Lintasan Pertama data yang diperoleh dengan menggunakan alat Geolistrik (Restivity Meter) adalah nilai resistivitas semu bervariasi karena struktur bawah tanah sangat bervariasi, nilainya berkisar antara $4,84 \Omega \mathrm{m}$ sampai dengan $105 \Omega \mathrm{m}$. Pada panjang lintasan 155 meter dengan jarak tiap elektroda 5 meter setelah diinversikan dengan Software Res2Dinv diperoleh gambar penampang seperti gambar 2 . di bawah :

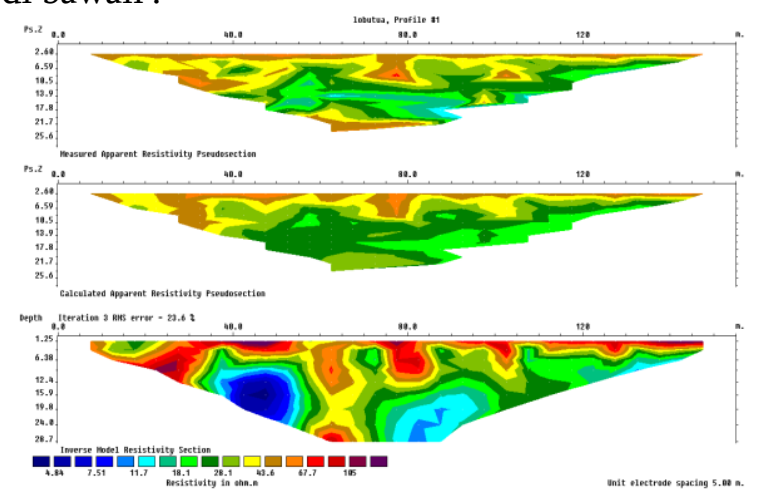

Gambar 2. Penampang Kontur Resistivitas Pertama

Berdasarkan penampang kontur resistivitas pada lintasan pertama, setiap warna memiliki nilai resistivitas yang berbeda. Warna biru pada kedalaman 9,39 meter sampai 24,0 meter menandakan nilai resistivitas yang rendah yaitu berkisaran antara $4,84-11,7 \Omega \mathrm{m}$, sedangkan warna hijau dan kuning pada kedalaman sekitar 3.81 meter sampai 28,7 meter, nilai resistivitasnya semakin tinggi dari nilai sebelumnya yaitu berkisar antara $18,1-43,6 \Omega \mathrm{m}$, dan warna merah dan ungu menandakan nilai resistivitas tertinggi pada setiap gambar penampang berkisar antara 67,7 - $105 \Omega \mathrm{m}$. Maka jenis tanah/batuan lapisan penyusun dapat diinterpretasikan seperti pada tabel 3 .

Tabel 3. Interpetrasi Lintasan Pertama

\begin{tabular}{cccc}
\hline No & $\begin{array}{c}\text { Kedalaman } \\
(\mathrm{m})\end{array}$ & $\begin{array}{c}\text { Resistivitas } \\
(\mathrm{\Omega m})\end{array}$ & Interpretasi \\
\hline 1. & $1,25-9,39$ & $67,7-105$ & Tanah liat/Lempung \\
2. & $9,39-24,0$ & $4,84-11,7$ & Tanah lanau lembek \\
3. & $3.81-28,7$ & $18,1-43,6$ & Tanah liat/Lempung \\
\hline
\end{tabular}

Berdasarkan tabel 2. pada kedalaman 1,25 meter sampai 28,7 meter belum terdeteksi lapisan keras dan struktur batuan pada bawah permukaan tanah. Seperti yang telah ditunjukkan dengan warna merah dan ungu yang terdapat pada lapisan permukaan atas pada kedalaman 1,25 meter sampai 9,39 meter yang memiliki nilai resistivitas 67,7 - $105 \Omega \mathrm{m}$ merupakan tanah liat/lempung bercampur dengan pasir (berdasarkan tabel 2.3) yang merupakan hasil pemadatan pondasi dari masyarakat sekitar. Sementara pondasi suatu bangunan dinyatakan layak apabila terdapat lapisan batuan dasar berkekar terisi tanah kering dengan nilai resistivitas lebih dari 300 $\Omega \mathrm{m}$ kemudian dilakukan pemadatan tanah agar mendapat tekstur lapisan tanah yang kuat untuk pondasi dari suatu bangunan (Syamsurizal dkk, 2013). Daerah penelitian ini memiliki nilai resistivitas sangat rendah, dikarenakan daerah penelitian merupakan daerah pesisir dan pori-pori batuan terisi air laut yang merupakan larutan konduktif.

Pada Lintasan Kedua data yang diperoleh dengan menggunakan alat Geolistrik (Restivity Meter) adalah nilai resistivitas semu bervariasi karena struktur bawah tanah sangat bervariasi, nilainya berkisar antara $0,856 \Omega \mathrm{m}$ sampai dengan 165 $\Omega \mathrm{m}$. Pada panjang lintasan 155 meter dengan jarak tiap elektroda 5 meter setelah 
diinversikan dengan Software Res2Dinv diperoleh gambar penampang seperti gambar 3. di bawah :

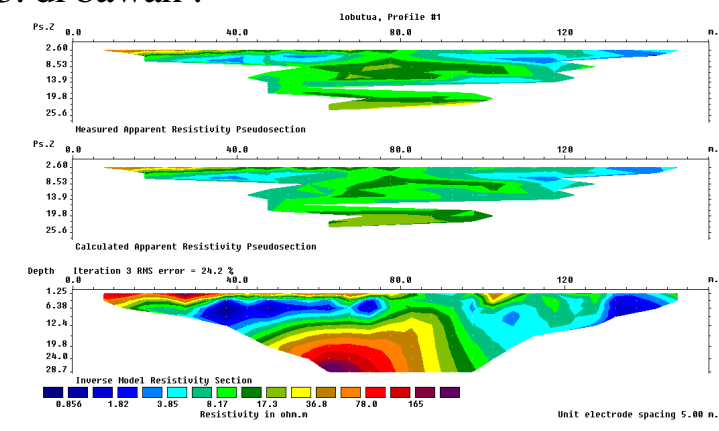

Gambar 3. Penampang Kontur Resistivitas Kedua

Berdasarkan penampang kontur resistivitas pada lintasan pertama, setiap warna memiliki nilai resistivitas yang berbeda. Warna biru pada kedalaman 1,25 meter sampai 16,1 meter menandakan nilai resistivitas yang rendah yaitu berkisan antara $0,856-3,85 \Omega \mathrm{m}$, sedangkan warna hijau dan kuning pada kedalaman sekitar 6,38 meter sampai 19,8 meter, nilai resistivitasnya semakin tinggi dari nilai sebelumnya yaitu berkisar antara $17,3-36,8 \Omega \mathrm{m}$, dan warna merah dan ungu menandakan nilai resistivitas tertinggi pada setiap gambar penampang berkisar antara 78,0 - $165 \Omega \mathrm{m}$. Maka jenis tanah/batuan lapisan penyusun dapat diinterpretasikan seperti pada tabel 4 .

Tabel 4. Interpetrasi Lintasan Kedua

\begin{tabular}{cccc}
\hline No & $\begin{array}{c}\text { Kedalaman } \\
(\mathrm{m})\end{array}$ & $\begin{array}{c}\text { Resistivitas } \\
(\Omega \mathrm{m})\end{array}$ & Interpretasi \\
\hline 1. & $1,25-16,1$ & $0,856-3,85$ & Tanah lanau lembek \\
2. & $6,38-19,8$ & $17,3-36,8$ & Tanah liatLempung \\
3. & $19,8-28,7$ & $78,0-165$ & $\begin{array}{c}\text { Batuan Dasar (Batuan } \\
\text { pasir)/Lempung }\end{array}$ \\
\hline
\end{tabular}

Berdasarkan gambar 3. pada kedalaman 1,25 meter sampai 16,1 meter belum terdeteksi lapisan keras dan struktur batuan pada bawah permukaan tanah. Sementara pondasi suatu bangunan dinyatakan layak apabila terdapat lapisan batuan dasar berkekar terisi tanah kering dengan nilai resistivitas lebih dari 300 $\Omega m$ kemudian dilakukan pemadatan tanah agar mendapat tekstur lapisan tanah yang kuat untuk pondasi dari suatu bangunan (Syamsurizal dkk, 2013). Seperti yang telah ditunjukkan dengan warna merah dan ungu yang terdapat pada lapisan bawah pada kedalaman 19,8 meter sampai 28,7 meter yang memiliki nilai resistivitas 78,0 - $165 \Omega \mathrm{m}$ merupakan Batuan dasar berisi tanah lembek (berdasarkan tabel 2.3). Daerah penelitian ini memiliki nilai resistivitas sangat rendah, dikarenakan daerah penelitian merupakan daerah pesisir dan pori-pori batuan terisi air laut yang merupakan larutan konduktif.

\section{KESIMPULAN DAN SARAN}

Daerah Pesisir Pantai kahona memiliki jenis batuan dasar berupa batuan pasir pada kedalaman lebih dari 28,7 meter yang terdapat pada lintasan kedua dan nilai resistivitas yang masih rendah berupa tanah liat/lempung yang memiliki nilai resistivitas berkisar antara 67,7 $105 \Omega \mathrm{m}$ pada kedalaman 1,25 - 28,7 meter di daerah lintasan pertama dan untuk lintasan kedua memiliki nilai resistivitas berkisar antara 0,856 - 3,85 $\Omega \mathrm{m}$ pada kedalaman 1,25 - 28,7 meter. Berdasarkan hasil penelitian di daerah pesisir Pantai Kahona belum dapat di rekomendasikan untuk pembangunan gedung bertingkat karena tidak terdeteksinya lapisan keras dan struktur batuan pada bawah permukaan tanah.

Bedasarkan nilai interpretasi pada penampang lintasan pertama dan lintasan kedua tidak terdeteksi adanya lapisan keras pada bawah permukaan dikarenakan rendahnya nilai resistivitas yang terukur di daerah penelitian tersebut.

Dilihat dari lokasi penelitian di daerah pesisir pantai, maka perlu dilakukan penelitian lebih lanjut dengan membuat jalur lintasan saling menyimpang atau diagonal agar keakuratan data yang diperoleh dapat maksimal. Kemudian pada lintasan kedua di kedalaman 19,8 - 28,7 meter sudah diperoleh berupa lapisan batuan dasar. Jadi, dapat dilakukan membuat stuktur pondasi bangunan yang dalam dan kuat agar dapat dilakukan pembangunan gedung bertingkat di daerah tersebut. Pemodelan penampang bawah permukaan juga dapat dikembangkan secara tiga dimensi dengan menggunakan Software Res3Dinv sehingga diperoleh gambaran lapisan keras yang lebih baik.

\section{DAFTAR PUSTAKA}

Badan Pusat Statistik, Kabupaten Tapanuli Tengah., (2012), Katalog Kecamatan 
Andam Dewi Dalam Rangka Andam

Dewi In Figure, Pandan.

Pramudiya, A. (2008), Kajian Pengelolaan

Daratan Pesisir Berbasis Zonasi Di

Provinsi Jambi., Tesis, Program

Pascasarjana, Universitas Diponegoro,

Semarang.

Selawati Eti.(2013), Pendeteksian Struktur

Tanah Dan Batuan Dengan Metode

geolistrik Resistivity Konfigurasi

Schlumberger Di Daerah Pesisir Pantai

Sialang Buah Kabupaten Serdang

Begadai, Skripsi. Medan : Universitas

Negeri Medan.

Soebowo.(2009), Sifat Keteknikan bawah

Permukaan Di Daerah pesisir Cilacap

Provinsi Jawa Tengah, Vol.19, No.2.

LIPI, Bandung.

Syamsurizal, Cari, Darsono.(2013), Aplikasi

Metoda Resistivitas Untuk Identifikasi

Litologi Batuan Sebagai Studi Awal

Kegiatan Pembangunan Pondasi

Gedung. Indonesian Journal of Applied Physics Vol.3 No.1

Telford, W. M., Geldart, L. P., dan Sherif, R.E.,(1990), Applied Geophysics, Cambridge University Press, New York 